\title{
Recyclable deep eutectic solvent for the production of cationic nanocelluloses
}

Panpan Li, ${ }^{a}$ Juho Antti Sirviö, ${ }^{a}$ Bright Asante, ${ }^{b}$ and Henrikki Liimatainen*,a

${ }^{\text {a }}$ Fibre and Particle Engineering Research Unit, University of Oulu, P.O. Box 4300, FI-90014 Finland

${ }^{\mathrm{b}}$ Wood Materials Science, University of Eastern Finland, P. O. Box 111, FI-80101, Finland

Henrikki Liimatainen; Henrikki.Liimatainen@oulu.fi (corresponding author)

Panpan Li; Panpan.Li@oulu.fi

Juho Antti Sirviö; Juho.Sirvio@oulu.fi

Bright Asante; basante1991@gmail.com

*Corresponding Author

E-mail: Henrikki.Liimatainen@oulu.fi

Tel.: +358 505659711 Fax: +3588344084 


\section{Highlights}

- A new deep eutectic solvent was developed to produce cationic cellulose

- Both cationic cellulose nanofibrils and cellulose nanocrystals can be produced

- This deep eutectic solvent can be re-used over 5 times at stable efficiency

- No additional chemical is needed for the reproduction of cationic cellulose

Graphical abstract

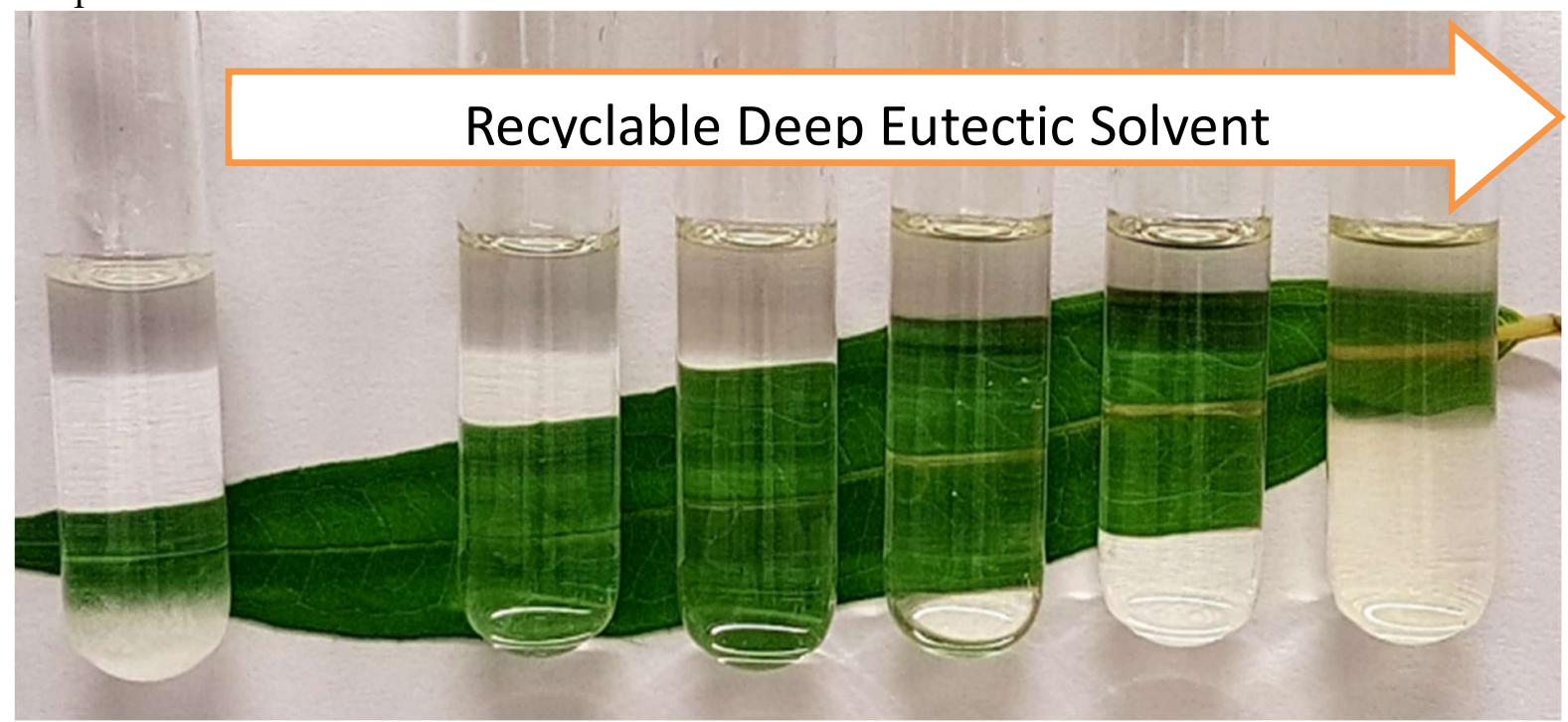




\section{ABSTRACT:}

Deep eutectic solvents (DESs) are potential green systems that can be used as reagents, extraction agents and reaction media. DESs are often biodegradable, easy to prepare and have low toxicity. In this work, a recyclable DES formed from aminoguanidine hydrochloride and glycerol (AhG) was used as a reaction medium and reagent (aminoguanidine hydrochloride) for the production of cationic nanocelluloses. Under mild conditions (i.e., a reaction time of $10 \mathrm{~min}$ at $70^{\circ} \mathrm{C}$ ), dialdehyde celluloses (DACs) with two different aldehyde contents $\left(2.18\right.$ and $\left.3.79 \mathrm{mmol} \mathrm{g}^{-1}\right)$ were cationized by AhG DES to form cationic dialdehyde celluloses (CDACs). Both CDACs achieved a similar high charge density of approximately $1.1 \mathrm{mmol} \mathrm{g}^{-1}$. At $80^{\circ} \mathrm{C}$ (for $10 \mathrm{~min}$ ), a very high cationic charge density of $2.48 \mathrm{mmol} \mathrm{g}^{-1}$ was obtained. The recyclability of AhG DES was demonstrated by reusing it five times without decreasing the reaction efficiency. In particular, due to the low consumption of amoniguanidine hydrochloride, high recycling efficiency could be achieved without the use of any additional chemicals. The cationized celluloses, CDACs, were further mechanically disintegrated to obtain cationic nanocelluloses. According to the initial aldehyde content of DACs, the morphology of the nanocellulose could be tailored to produce highly cationic cellulose nanofibrils (CNFs) or cellulose nanocrystals (CNCs). Transmission electron microscopy confirmed that individual CNFs and CNCs with an average width of $4.6 \pm 1.1 \mathrm{~nm}$ and $5.7 \pm 1.3$ $\mathrm{nm}$, respectively, were obtained. Thus, the results presented here indicate that the AhG DES is a promising green and recyclable way of producing cationized CNFs and CNCs.

KEYWORDS: Cationization, Nanocellulose, Recycle, Deep eutectic solvents. 


\section{INTRODUCTION}

2 Selection of the appropriate reaction medium is critical to many chemical processes, and c.a.

$380 \%$ of all consumed chemicals are used as solvents for different purposes.(Cruz, Jordão, \&

4 Branco, 2017) Traditional solvents are usually prepared from non-renewable and toxic

5 petrochemical derivatives,(Gu \& Jérôme, 2010) and they are often highly volatile, flammable and

6 problematic for the environment.(Alonso et al., 2016) As a consequence of the depletion of oil

7 resources and increasing environmental awareness, there has been growing interest in exploring

8 alternative solvents such as water,(C.-J. Li \& Chen, 2006) fluorinated compounds,(Khaksar, 2015)

9 and ionic liquids (ILs)(Imperato, König, \& Chiappe, 2007) in the past decade. Although promising

10 results have been reported, obvious limitations (such as high cost and requirement for high purity

11 of ILs) still restrict their practical use in many cases. Therefore, new green and easily available

12 solvents are in high demand. (Q. Zhang, De Oliveira Vigier, Royer, \& Jérôme, 2012)

13 Currently, deep eutectic solvents (DESs) are of particular interest. The complexation of a hydrogen

14 bond acceptor (HBA, which is typically a halide salt of quaternary ammonium) with a hydrogen

15 bond donor (HBD, e.g., urea and glycerol) results in the formation of an eutectic mixture with a

16 relatively low melting point, and this is how DESs are usually produced. (Paiva et al., 2014; J. A.

17 Sirviö, Visanko, \& Liimatainen, 2015; Smith, Abbott, \& Ryder, 2014; Wagle, Zhao, \& Baker,

18 2014; Q. Zhang et al., 2012) DES candidates are abundant, and they can be produced from

19 inexpensive, biodegradable and recyclable ingredients.(Ilgen et al., 2009; Singh, Lobo, \&

20 Shankarling, 2011; J. A. Sirviö, Visanko, Ukkola, \& Liimatainen, 2018) Similar to ILs, DESs

21 exhibit good solvent capacity and have a low vapor pressure that limits VOC emissions.(J. A. 
Sirviö, Visanko, et al., 2015; J. A. Sirviö, Visanko, \& Liimatainen, 2016; Smith et al., 2014) However, it is much easier to prepare DESs (by straightforward mixing and heating), and they are less sensitive to impurities and usually cheaper to prepare than ILs.(Wang et al., 2016) These unique properties make DESs promising green solvents and chemicals for sustainable biomaterial production processes.

Cellulose is known as the most abundant natural biopolymer on earth. In addition, renewability, biodegradability, and low toxicity are all inherent green characteristics of cellulose.(Credou \& Berthelot, 2014; Schenzel, Hufendiek, Barner-Kowollik, \& Meier, 2014) Nanocelluloses, which are described as nano-structured celluloses and are often referred to as elongated cellulose nanofibrils (CNFs) or rigid cellulose nanocrystals (CNCs), have been considered as future biomaterials in recent years.(Moon, Martini, Nairn, Simonsen, \& Youngblood, 2011) Depending on the raw materials and production methods, CNFs are mostly 3-100 nm in width and several micrometers in length,(Klemm et al., 2011) whereas CNCs have a similar diameter but are shorter and have a more rod-like crystalline structure. Nanocelluloses possess certain inherent chemical characteristics (e.g., three reactive hydroxyl groups in each repeating unit) of celluloses, are lightweight,(Mohieldin, Zainudin, Paridah, \& Ainun, 2011) and have high mechanical strength(Oksman, Mathew, Bondeson, \& Kvien, 2006) and good thermal stability.(P. Li, Sirviö, Haapala, \& Liimatainen, 2017) These favorable properties make nanocelluloses a promising resource in advanced applications such as UV-absorbing fillers for nanocomposites,(J. A. Sirviö, Visanko, Heiskanen, \& Liimatainen, 2016) substrates for organic solar cells,(Zhou et al., 2014) agents for mineral flotation(O. Laitinen et al., 2016; Ossi Laitinen et al., 2014) and stabilizers of oil-water emulsions.(Ojala, Sirviö, \& Liimatainen, 2016) 
Typically, CNFs are produced through a mechanical nanofibrillation procedure (e.g., refining, grinding, and homogenization), which requires a significant amount of energy due to the highly ordered hydrogen bond network of cellulose.(Baati, Magnin, \& Boufi, 2017; J. A. Sirviö, Hasa, et al., 2015) Nevertheless, the high energy consumption can be reduced with the use of chemically modified,(H. Liimatainen, Visanko, Sirviö, Hormi, \& Niinimaki, 2012; Henrikki Liimatainen, Suopajärvi, Sirviö, Hormi, \& Niinimäki, 2014; Saito, Nishiyama, Putaux, Vignon, \& Isogai, 2006; Selkälä, Sirviö, Lorite, \& Liimatainen, 2016) enzyme-assisted,(Henriksson, Henriksson, Berglund, \& Lindström, 2007; Shahid, Mohammad, Chen, Tang, \& Xing, 2016) or solvent-disintegrated(P. Li et al., 2017; J. A. Sirviö, Visanko, et al., 2015) pretreatment approaches.(Siró \& Plackett, 2010a) Unlike CNFs, CNCs can be conventionally fabricated by simple acidic (e.g., sulfuric,(Bondeson, Mathew, \& Oksman, 2006) hydrochloric,(Yu et al., 2013) or phosphoric acid(Camarero Espinosa, Kuhnt, Foster, \& Weder, 2013)) hydrolysis of the amorphous regions of cellulose, which releases the hard crystalline parts of cellulose. However, there are noticeable limitations to acidic hydrolysis methods, such as material corrosion, sensitive reaction conditions, low production yield,(Corrêa, de Morais Teixeira, Pessan, \& Mattoso, 2010; Lu et al., 2016) and fiber aggregation.(Araki, Wada, Kuga, \& Okano, 1998) Therefore, oxidation-based methods such as TEMPO-,(Qin, Tong, Chin, \& Zhou, 2011) persulfate(Leung et al., 2011; K. Zhang et al., 2016) and periodate oxidation(Visanko et al., 2014) have been developed not only to compensate for the shortcomings of acidic hydrolysis methods, but also to expand functionalized CNC production.(Montanari, Roumani, Heux, \& Vignon, 2005; J. A. Sirviö, Visanko, Heiskanen, et al., 2016; Visanko et al., 2014)

The introduction of cationic groups on cellulose fibers can enhance nanocellulose production and prevent the aggregation of nanocelluloses due to electrostatic repulsion.(Visanko et al., 2014) In 
addition, introduction of cationically charged groups combined with alkyl chains, such as aminated structures, to the hydrophilic backbone of cellulose can result in the formation of amphiphilic nanocelluloses, which have potential for use as a stabilizer in oil-water emulsions,(Visanko et al., 2014) flocculation agent in dewatering,(Suopajärvi, Sirviö, \& Liimatainen, 2017a) or a colloid aggregation agent.(Henrikki Liimatainen et al., 2014) Previously, cationized nanocelluloses have been synthesized in epoxypropyltrimethylammonium chloride,(Hasani, Cranston, Westman, \& Gray, 2008) imidazolium,(Eyley \& Thielemans, 2011) pyridinium(Jasmani, Eyley, Wallbridge, \& Thielemans, 2013) and water.(Hua et al., 2014; J. A. Sirviö et al., 2014a; J. Sirviö, Honka, Liimatainen, Niinimäki, \& Hormi, 2011; Yang \& van de Ven, 2016)

DESs have been used as alternative green routes to produce both non-derivatized (Ossi Laitinen, Suopajärvi, Österberg, \& Liimatainen, 2017; P. Li et al., 2017; J. A. Sirviö, Visanko, et al., 2015; Suopajärvi, Sirviö, \& Liimatainen, 2017b) and anionic(Ossi Laitinen, Ojala, Sirviö, \& Liimatainen, 2017; Selkälä et al., 2016; J. A. Sirviö, Visanko, \& Liimatainen, 2016; J. A. Sirviö \& Visanko, 2017) nanocelluloses, but there was very few reports about its use for the fabrication of cationized nanocelluloses.(J. A. Sirviö, n.d.) Thus, to the best of our knowledge, this is the first time that a recyclable and effective DES was developed to produce cationic nanocelluloses. In this work, a DES produced using aminoguanidine hydrochloride and glycerol (AhG) was used as a reaction medium and reagent (aminoguanidine hydrochloride) for cationization of dialdehyde cellulose (DAC). Birch cellulose was first oxidized to DAC using recyclable sodium periodate(Jin, Li, Xu, \& Sun, 2015; Henrikki Liimatainen, Sirviö, Pajari, Hormi, \& Niinimäki, 2013; J. Zhang, Jiang, Dang, Elder, \& Ragauskas, 2008) and then cationized by the AhG DES to produce cationic dialdehyde celluloses (CDACs) under different temperatures and reaction times. The CDACs that were synthesized at $70^{\circ} \mathrm{C}$ for $10 \mathrm{~min}$ were selected and further mechanically nanofibrillated to 
obtain cationized nanocelluloses. The recyclability and yield of the DES were analyzed. The charge densities of CDACs were investigated by polyelectrolytic titration, and attenuated total reflection infrared (ATR-IR) spectroscopy was used for the chemical characterization of celluloses. Cationized nanocelluloses were characterized by transmission electron microscopy (TEM).

\section{Materials and methods}

\subsection{Materials}

Bleached kraft birch (Betula pendula) pulp sheets were used as cellulose raw material after they were disintegrated in deionized water. The properties of the pulp have been determined in a previous study.(Henrikki Liimatainen, Sirviö, Haapala, Hormi, \& Niinimäki, 2011) Lithium chloride (99\%) and sodium periodate ( $>99 \%$ ) were obtained from Sigma Aldrich (Germany) to produce dialdehyde cellulose. Ethanol (96\%) and glycerol (97\%) (VWR, France) and aminoguanidine hydrochloride (>98\%) (Tokyo Chemicals Industry, Japan) were used for the cationization of dialdehyde cellulose. Sodium polyethylene sulfonate (PES-Na) from BTG (UK) was used as a polyelectrolyte to determine the cationic charge. Uranyl acetate dihydrate (98\%) was from Polysciences (Germany). Polylysine solution (0.01\%) was from Sigma Aldrich (Germany). Deionized water was also used throughout the study.

\subsection{Synthesis of CDACs in the AhG DES}

DAC was obtained from birch pulp by a slightly modified version of the sodium periodate oxidation method reported previously.(Dash, Elder, \& Ragauskas, 2012; Sirvio, Hyvakko, Liimatainen, Niinimaki, \& Hormi, 2011) Briefly, $10 \mathrm{~g}$ (abs.) of birch pulp was diluted with 1000 
$111 \mathrm{~g}$ of deionized water, and the suspension was heated to a final temperature of $55^{\circ} \mathrm{C}$ or $75^{\circ} \mathrm{C}$ in an

112 oil-bath system. Following this, $18 \mathrm{~g}$ of lithium chloride $(\mathrm{LiCl})$ and $8.2 \mathrm{~g}$ of sodium periodate

$113\left(\mathrm{NaIO}_{4}\right)$ were added and left to react with cellulose for $3 \mathrm{~h}$ at their respective temperatures. The

114 mixed reaction suspensions were fully covered with an aluminum foil to avoid light-induced

115 decomposition of periodate. The products were filtered, washed with $1000 \mathrm{ml}$ of a 50:50

116 ethanol:water solution, mixed in $500 \mathrm{ml}$ ethanol twice for $15 \mathrm{~min}$, and filtrated. According to the

117 reaction temperature $\left(55^{\circ} \mathrm{C}\right.$ or $\left.75^{\circ} \mathrm{C}\right)$, the DAC products were labeled as DAC55 or DAC75.

118 The AhG DES was prepared by mixing $75 \mathrm{~g}$ aminoguanidine hydrochloride and $125 \mathrm{~g}$ glycerol 119 in a molar ratio of 1:2 in a Scott bottle. The mixture was preheated at $90^{\circ} \mathrm{C}$ in an oil bath to obtain 120 a clear liquid, and then adjusted to the desired reaction temperatures $\left(70,80,90\right.$, and $\left.100^{\circ} \mathrm{C}\right)$.

121 Following this, $10 \mathrm{~g}$ (abs.) DAC55 or DAC75 was added into the DES, which was stirred 122 continuously with a magnetic bar for a set of reaction times $(5,10,15,30$ and $60 \mathrm{~min})$ at the desired 123 temperatures. The reaction bottle was removed from the oil-bath system and $250 \mathrm{ml}$ of ethanol 124 was added. The product suspension was filtrated and washed twice with $500 \mathrm{ml}$ of ethanol. The 125 filtrate (DES-ethanol solution) was collected for the next cationization cycle. The yield of CDACs 126 was recorded.

\subsection{ATR-IR}

The FTIR spectra of birch cellulose, DAC75 and CDAC75 (synthesized from the original DES

129 at $70^{\circ} \mathrm{C}$ for $10 \mathrm{~min}$ ) were recorded with a Bruker IR spectrometer (Bruker Tensor II FTIR

130 Spectrometer, USA) equipped with an attenuated total reflection (ATR) accessory. The samples 131 were prepared by pressing $0.2 \mathrm{~g}$ (abs.) dried sample into a pellet. 
134 nanofibrillation. Cationized nanocelluloses were produced by mechanical disintegration of $1 \%$ 135 CDAC55 or CDAC75 solution with a microfluidizer (Microfluidics M-110EH-30, USA). Both

136 CDAC55 and CDAC75 were treated similarly: they were first stirred with a magnetic bar for 10 137 min and then passed through a pair of chambers (400 and $200 \mu \mathrm{m})$ twice in a microfluidizer under 138 a pressure of 1000 bars.

The morphological features of the cationized nanocelluloses were observed with the help of

141 a Tecnai G2 Spirit transmission electron microscope (FEI Europe, Eindhoven, The Netherlands).

142 Nanocellulose samples were diluted with deionized water into a $0.01 \%$ solution $(\mathrm{w} / \mathrm{w})$, and a tiny 143 droplet $(7 \mu \mathrm{L})$ of polylysine used as adhesive of nanocellulose sample(Marsich et al., 2012) was

144 first dosed on the top of a Butvar and carbon-coated copper grid and left for 1 min. Excess 145 polylysine was wiped off with a filter paper. Similarly, $7 \mu \mathrm{L}$ of the nanocellulose sample solution 146 was then dropped, stayed and removed from the grid. Finally, a drop of negative staining agent, 147 uranyl acetate $(2 \%[\mathrm{w} / \mathrm{v}])$, was applied using the same procedure. The stained samples were dried 148 at room temperature and were later analyzed at $100 \mathrm{kV}$ under standard conditions. Images were

149 taken with a Quemesa CCD camera. The width of individual nanofibrils or nanocrystals was 150 measured using the iTEM image analysis software (Olympus Soft Imaging Solutions GMBH, 151 Munster, Germany). The data obtained are presented as the mean and standard errors.

The cationic charge density of CDACs was determined using the polyelectrolyte titration 154 method with a particle charge detector (BTG Mütek PCD-03, Germany). The CDACs were diluted 
with deionized water into a $0.01 \%$ solution and stirred with a magnetic stirrer at room temperature

156 for $30 \mathrm{~min}$. Then, $10 \mathrm{ml}$ of well-dispersed CDAC suspension was titrated with the sodium

157 polyethylene sulfonate (PES-Na) polyelectrolyte. The charge density was calculated based on the 158 consumption of PES-Na. The results are the average of two trials with minor difference.

\subsection{Recycling of the AhG DES}

The collected filtrate containing the AhG DES and ethanol from the cationization reaction was distilled under reduced pressure at $50^{\circ} \mathrm{C}$ using a rotatory evaporator (Büchi rotavapor $\mathrm{R} 114$,

162 Switzerland) in a water bath. The recycled DES was reheated to $70^{\circ} \mathrm{C}$ and reused in the

163 cationization of DACs (10-min reaction), in a similar manner as described earlier. The recycling 164 was repeated five times without the use of any additional chemicals.

The yields of CDAC55 and CDAC75 were calculated by the measurement of mass differences, before and after chemical treatment. However, the yield of recycled DES was calculated by the measurement of mass differences, compared with original DES.

\subsection{Thermogravimetric Analysis}

Thermogravimetric analysis (TGA) of original AhG DES was carried out by a thermal analyzer

171 (Netzsch STA 449F3 apparatus) under air atmospheres; the air flow (dynamic air), at a constant rate of $60 \mathrm{~mL} \mathrm{~min} \mathrm{~m}^{-1}$. Approximate $20 \mathrm{mg}$ of well mixed AhG DES was added into an aluminum pan and was heated from 20 to $650{ }^{\circ} \mathrm{C}$ with a heating rate at $10{ }^{\circ} \mathrm{C} \mathrm{min}-1$. The decomposition

174 temperature (Td) was taken when the temperature at the onset point of the weight loss in the TGA 175 curve was obtained. 
The crystalline structures of the CDAC55 and CDAC75 were investigated using wide-angle Xray diffraction. Measurements were conducted on a Rigaku SmartLab $9 \mathrm{~kW}$ rotating anode diffractometer (Japan) equipped with a $\mathrm{Cu} \mathrm{K} \alpha$ radiation source $(\lambda=0.1542 \mathrm{~nm})$ at $45 \mathrm{kV}, 200 \mathrm{~mA}$. Specimens were prepared by pressing tablets with a thickness of $1 \mathrm{~mm}$ after freeze-drying the samples. Scans were taken over a $2 \theta$ (Bragg angle) range from $5^{\circ}$ to $50^{\circ}$ at a scanning speed of $2^{\circ}$ $\mathrm{s} \min ^{-1}$ using a step of $0.05^{\circ}$. The degree of the peak intensity of the main crystalline plane (200) diffraction $\left(\mathrm{I}_{200}\right)$ was located at $22.5^{\circ}$. The peak intensity associated with the amorphous fraction of cellulose $\left(\mathrm{I}_{\mathrm{am}}\right)$ was observed at $18.0^{\circ}$. Crystallinity index $(\mathrm{CrI})$ values were calculated according to the empirical Segal method. (Segal, Creely, A. E. Martin, \& Conrad, 2016)

$$
\operatorname{CrI}=\left(\frac{\mathrm{I}_{200}-\mathrm{I}_{\mathrm{am}}}{\mathrm{I}_{200}}\right) \times 100 \%
$$

\section{Results and discussion}

The AhG DES was prepared by aminoguanidine hydrochloride and glycerol in a molar ratio of 1:2. The cationization of DAC was conducted in AhG DES, in which glycerol was applied as an HBD to help with the formation of an efficient and continuously derivable DES from

192 aminoguanidine hydrochloride.(J. A. Sirviö, Visanko, et al., 2015; Smith et al., 2014; Wagle et al., 193 2014; W. Zhang, Barone, \& Renneckar, 2015) Glycerol is a well-known natural polyol that is often 194 obtained as a by-product of the transesterification of a triglyceride in natural fatty acid 195 production.(Wolfson, Dlugy, \& Shotland, 2007) Glycerol has the combined advantages of water 196 (which is renewable, inexpensive and abundant) and ILs (which has a high boiling point and low 
vapor pressure),(Gu \& Jérôme, 2010) which make it an alternative green medium for catalytic and non-catalytic reactions.(Kong et al., 2016; Wolfson et al., 2007) In addition to pure glycerol, glycerol-based solvent systems have also been reported as a reaction medium for organic synthesis,(García, García-Marín, \& Pires, 2014) as a co-solvent for biotransformation,(Hernáiz, Alcántara, García, \& Sinisterra, 2010; Wolfson, Dlugy, Tavor, Blumenfeld, \& Shotland, 2006) as a dual solvent-reagent system for hydrogenation reaction,(Cravotto et al., 2011; Díaz-Álvarez, Crochet, \& Cadierno, 2011) and as an HBD for DES formation.(Abbott et al., 2011; Abbott, Cullis, Gibson, Harris, \& Raven, 2007; Zhao \& Baker, 2013) In the literature, similar DESs formed by choline chloride-glycerol have also been studied and applied as a medium for the desulfurization of fuel and the absorption of $\mathrm{CO}_{2}$ and $\mathrm{SO}_{2}$.(Abbott et al., 2011; García et al., 2014) However, in the present case, the AhG DES was used as a derivatizing solvent for cellulose cationization.

\subsection{Cationization of DAC in AhG DES}

The reaction between DAC and aminoguanidine hydrochloride resulted in the formation of a stable imine bond, and thus could be used to introduce cationic groups to DAC (Figure 1).(J. A. Sirviö et al., 2014b; J. Sirviö et al., 2011) Here, DAC55 and DAC75 (which have an aldehyde content of 2.18 and $3.79 \mathrm{mmol} \mathrm{g}^{-1}$, respectively, as determined previously(Sirvio et al., 2011)) were successfully further cationized (CDAC55 and CDAC75) using a set of reaction times $(5,10$, $15,30$ and $60 \mathrm{~min})$ and temperatures $\left(70,80,90\right.$ and $\left.100^{\circ} \mathrm{C}\right)$. 


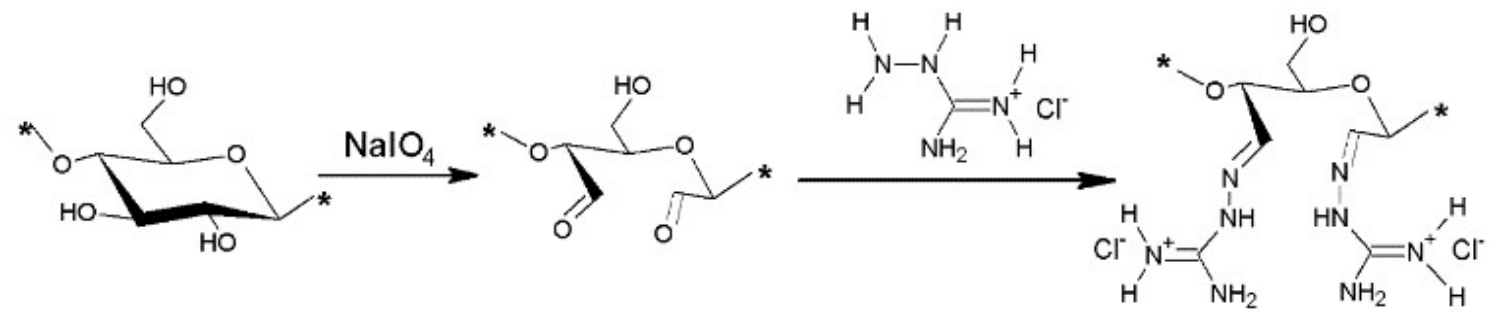

Figure 1. Cationization of cellulose using sequential periodate oxidation and imidization with aminoguanidine hydrochloride.

219 The original AhG DES that was formed by the mixing of aminoguanidine hydrochloride and glycerol became a clear and colorless liquid at $90^{\circ} \mathrm{C}$. The heating temperature was crucial to DES formation; i.e., a clear solution was obtained rapidly at 90 and $100^{\circ} \mathrm{C}$, but a more turbid solution was obtained at 70 and $80^{\circ} \mathrm{C}$. Therefore, the DES was first heated to $90^{\circ} \mathrm{C}$, and then the temperature was adjusted to the desired reaction temperature. The addition of DAC into DES (at a mass ratio of 1:20) resulted in the formation of a turbid mixture immediately, which is due to the efficient reaction and swelling of the DAC pulp in the AhG DES.(Selkälä et al., 2016; J. A. Sirviö, Visanko, et al., 2015)

The effects of different reaction temperatures and reaction times on the charge densities and yields of CDAC are presented in Figure 2. The results indicated that a high charge density, i.e., effective cationization, in the AhG DES was obtained when the reaction time was less than 15 min 230 (Figure $2 \mathrm{a}$ and $\mathrm{b}$ ). In a relative high temperature $\left(>70^{\circ}\right)$, the yield of CDAC55 started to decrease 231 when the reaction time was longer than $15 \mathrm{~min}$ (Figure 2c), whereas the yield of CDAC75 became 232 relatively stable after 30 min reaction (Figure $2 \mathrm{~d}$ ). However, in a mild temperature at $70^{\circ} \mathrm{C}$, both 233 CDAC55 and CDAC75 started to decrease their yield sharply after 30 min reaction. The increase in CDAC mass (yield $>100 \%)$ at low reaction times $(<10 \mathrm{~min})$ was due to the addition of large- 
attach to the CDAC could also lead to an unrealistic high yield. However, there was no direct relationship between the charge density and the yield, because the high charge density combined with elevated temperature and extended reaction time would also promote CDAC hydrolysis and dissolution, which in turn decreased the yield. For example, CDAC 75 synthesized at $90^{\circ} \mathrm{C}$ and 30 min had a high charge density of $2.19 \mathrm{mmol} \mathrm{g}^{-1}$, but a low yield of $50 \%$. However, when the reaction temperature and time were decreased to $80^{\circ} \mathrm{C}$ and 10 min respectively, CDAC75 was obtained with a high charge density of $2.48 \mathrm{mmol} \mathrm{g}^{-1}$ along with a yield of $105 \%$. Therefore, the 243 yields reflect the combination effects of the introduced cationic groups, the degree of CDAC 244 hydrolyzing and dissolution in DES and in ethanol during the washing, and the contribution of 245 impurities (small amount of glycerol from DES can be attached to dialdehyde cellulose by acetal 246 and hemiacetal formation).

247 Under the same DES reaction conditions, CDAC75 typically had higher charge densities than 248 CDAC55. This result was due to the higher initial aldehyde content of its precursor compared to 249 CDAC55.(J. Sirviö et al., 2011) In addition, there were clear trends for CDAC75, too: at all 250 temperatures, the charge densities increased when the reaction time was increased from 5 to 10 251 min (Figure $2 \mathrm{~b}$ ). In the case of CDAC55, the charge density increased steadily at $70^{\circ} \mathrm{C}$ with 252 prolonged reaction time. Moreover, there was no significant difference in charge densities in 253 response to changes in temperature or reaction time (Figure 2a). Therefore, applying the AhG DES 254 under mild conditions (reaction time of less than 15 min and temperatures of $70^{\circ} \mathrm{C}$ and $80^{\circ} \mathrm{C}$ ) 255 seems to be favorable for the production of cationized DAC with a high charge density and mass 256 yield. Overall, compared with previous catalyst-assisted cationization or cationization reactions that required several hours, ${ }^{75,76,87}$ AhG DES seems to be an effective solvent for the cationization 
DES could meet industrial needs on account of the low energy consumption and fast processing.
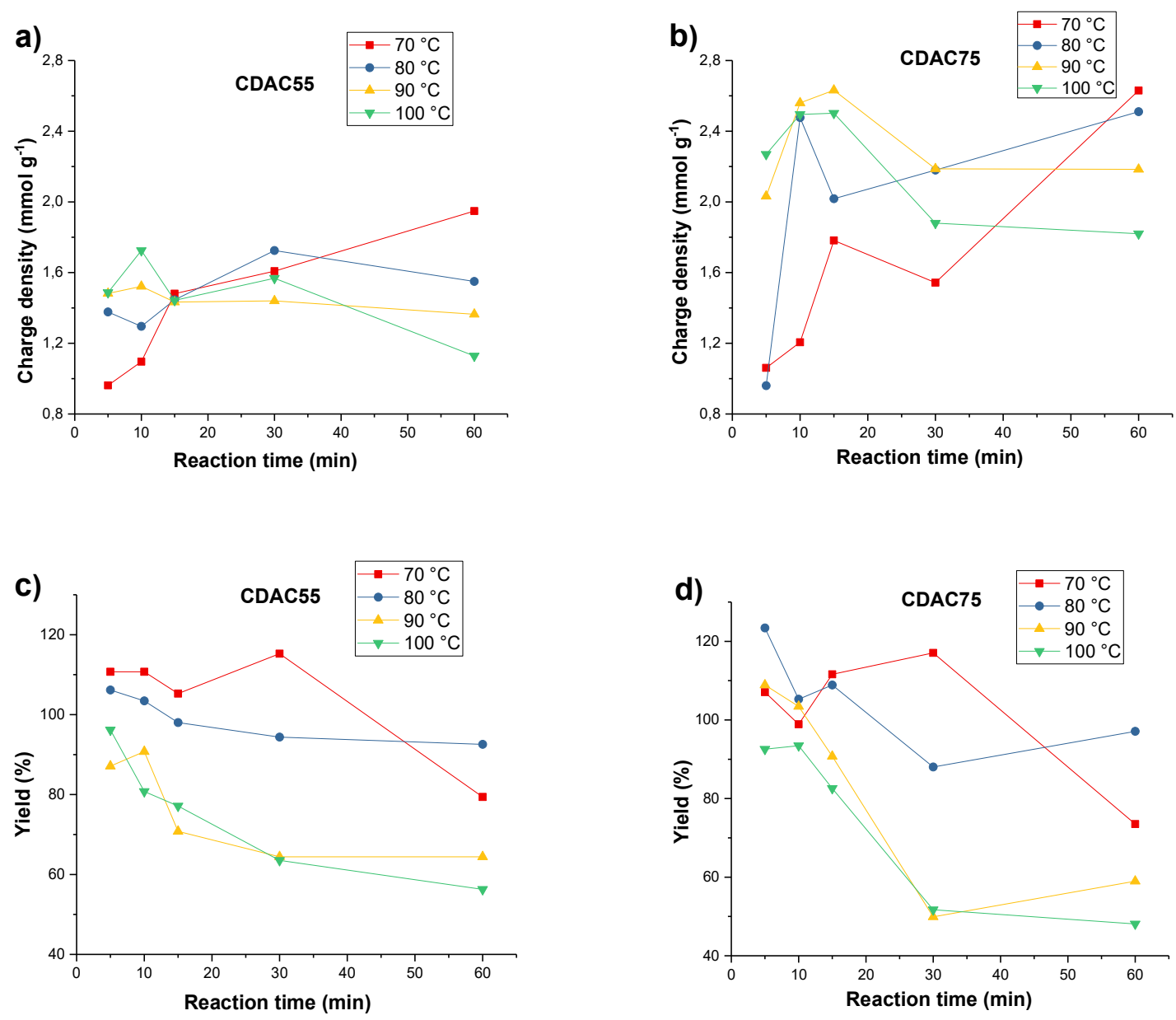

Figure 2. The charge density of CDAC55 (a) and CDAC75 (b), and the yield of CDAC55 (c) and CDAC75 (d), as a function of reaction time and temperature in cationization with AhG DES.

\subsection{Characteristics of cationized celluloses}

The original cellulose, DAC75 and AhG DES-synthesized CDAC75 (at $70^{\circ} \mathrm{C}$ for $10 \mathrm{~min}$ ) were characterized by ATR-IR (Figure 3). The spectra of DAC75 and CDAC75 presented characteristic cellulosic bands in the range of 4000-2995 $\mathrm{cm}^{-1}$ that corresponded to $\mathrm{OH}$ stretching, an adsorption band at $2900 \mathrm{~cm}^{-1}$ that corresponded to $\mathrm{CH}$ stretching vibration, and a band at $1430 \mathrm{~cm}^{-1}$ that was 
assigned to $\mathrm{HCH}$ and $\mathrm{CHO}$ in plane deformation vibrations.(Oh, Yoo, Shin, \& Seo, 2005; J. A.

271 Sirviö, Visanko, et al., 2015) The absorption band at $1728 \mathrm{~cm}^{-1}$, which is characteristic of the 272 aldehyde carbonyl group in DAC75, was replaced with new bands that appeared at $1674 \mathrm{~cm}^{-1}$ and $2731635 \mathrm{~cm}^{-1}$ in CDAC75 and corresponded to the carbon-nitrogen double bond of imines and 274 nitrogen-hydrogen bond bending, respectively. (J. A. Sirviö et al., 2014b; Y. Zhang, Jiang, \& 275 Chen, 1999). These findings indicated successful reaction between the aldehyde groups in DAC 276 and aminoguanidine hydrochloride in the AhG DES.

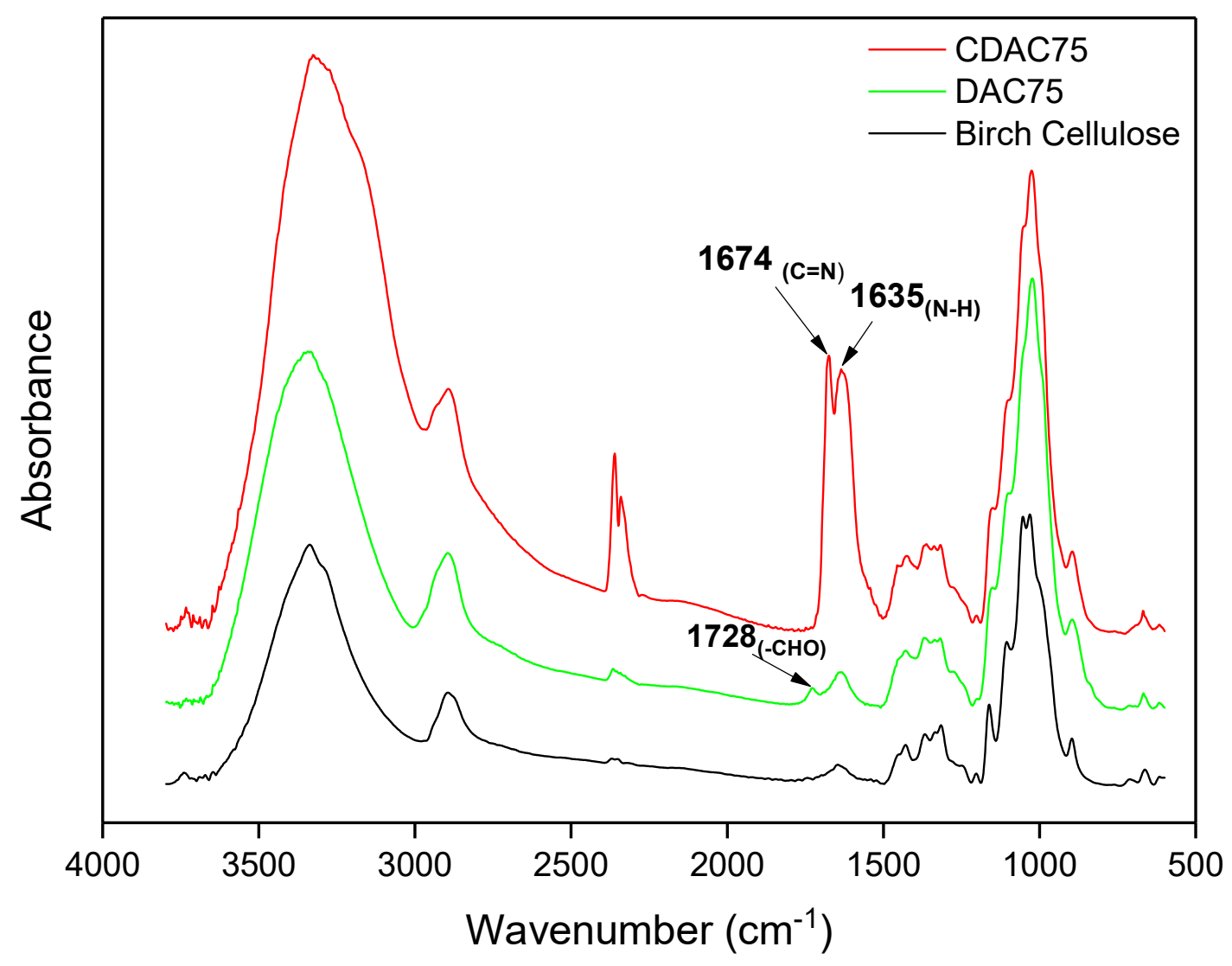

Figure 3. ATR-IR spectra of birch cellulose, DAC75 with the characteristic aldehyde band (1728 $\left.\mathrm{cm}^{-1}\right)$, and CDAC75 with the characteristic carbon-nitrogen double bond $\left(1674 \mathrm{~cm}^{-1}\right)$ and nitrogen280 hydrogen bond $\left(1635 \mathrm{~cm}^{-1}\right)$.

281 The reaction mechanisms of DAC cationization in the AhG DES can be explained in two ways:

282 (1) The AhG DES enabled the aldehyde groups of DAC to form stable imine structures with 283 aminoguanidine hydrochloride. The driving force of the reaction was the formation of the 
284 conjugated imine structure.(Clayden, Greeves, \& Warren, 2012) (2) The AhG DES worked 285 simultaneously as a cellulose disintegrating medium by disrupting the internal and external 286 hydrogen and hemiacetal/acetal bonds of DAC, which in turn enhanced the reaction efficiency and 287 later promoted the mechanical disintegration process to lead to the production of functionalized 288 nanocelluloses.(P. Li et al., 2017) In addition, the AhG DES could increase the reactivity of the 289 aldehyde groups through formation of hydrogen bonds with carbonyl and thus increased the 290 electrophilicity of the aldehyde carbon.(Guigo, Mazeau, Putaux, \& Heux, 2014)

291 The XRD spectra of CDAC55 and CDAC75 (Figure 4) indicated an increase in crystallinity. I.e., 292 after the DES cationization, the crystallinity of CDAC55 and CDAC75 were $63.2 \%$ and $64.9 \%$, 293 which were higher than the original birch pulp $(56.6 \%)$ and previously reported to cationic 294 cellulose synthesized in water (J. A. Sirviö et al., 2014b). These results suggested the dissolution 295 of the amorphous parts of cellulose during AhG DES cationization. 


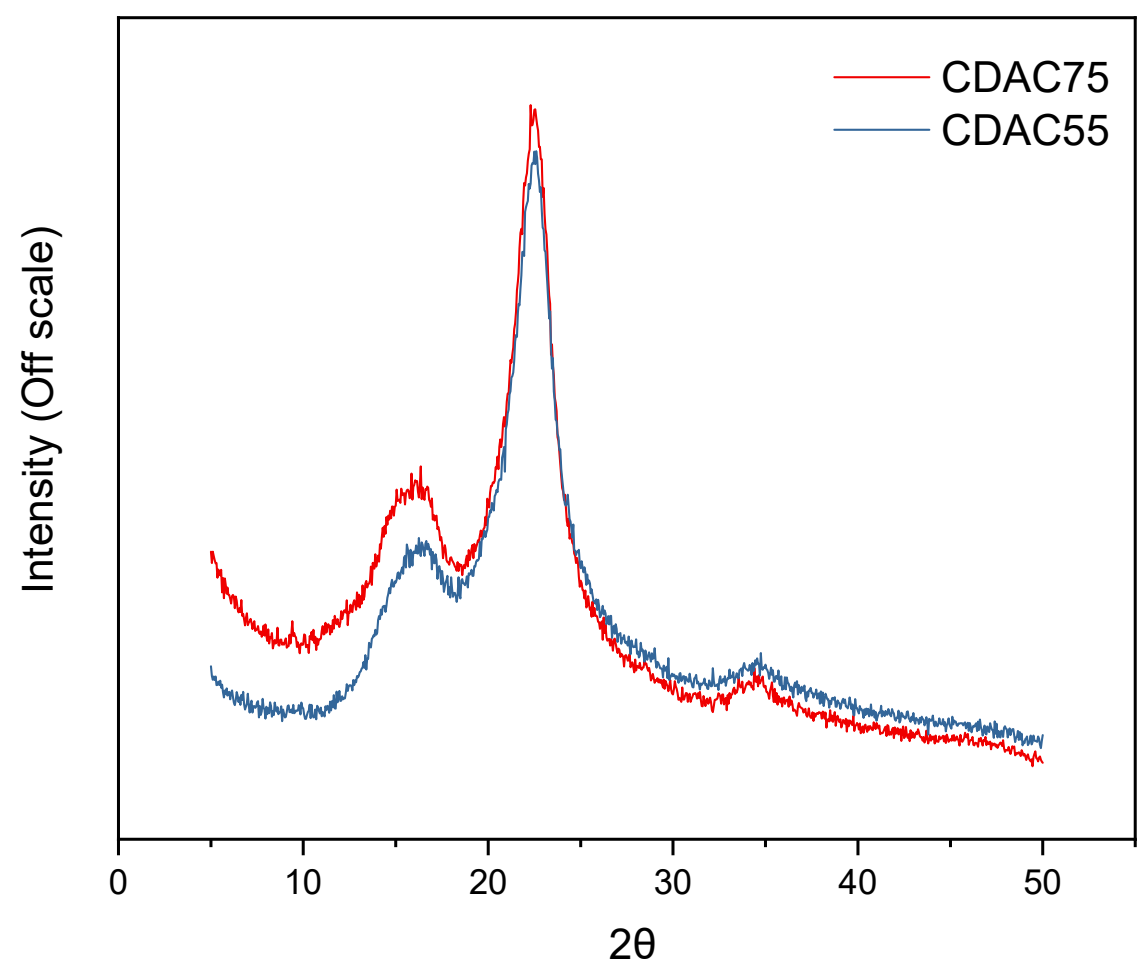

Figure 4. X-ray diffraction spectra of CDAC55 and CDAC75.

\subsection{Cationized nanocelluloses}

CDAC55 and CDAC75 treated with $\mathrm{AhG}$ DES at $70^{\circ} \mathrm{C}$ for 10 min were selected for 301 mechanical disintegration with a microfluidizer, owing to their relatively high charge density (0.918 and $1.206 \mathrm{mmol} \mathrm{g}^{-1}$, respectively). Unlike the raw cellulose and DAC fibers, there was no chamber clogging(Carrillo, Laine, \& Rojas, 2014; Siró \& Plackett, 2010b) with the AhG-treated

304 CDAC55 and CDAC75. Both the samples smoothly passed through the microfluidizer chambers.

305 The introduced repulsive positive surface charges and the weakened hydrogen bonding network 306 of the cellulose fibers were useful for the mechanical disintegration. Furthermore, homogenous, 307 gel-like materials were obtained after the first pass through the microfluidizer, whereas the visual 


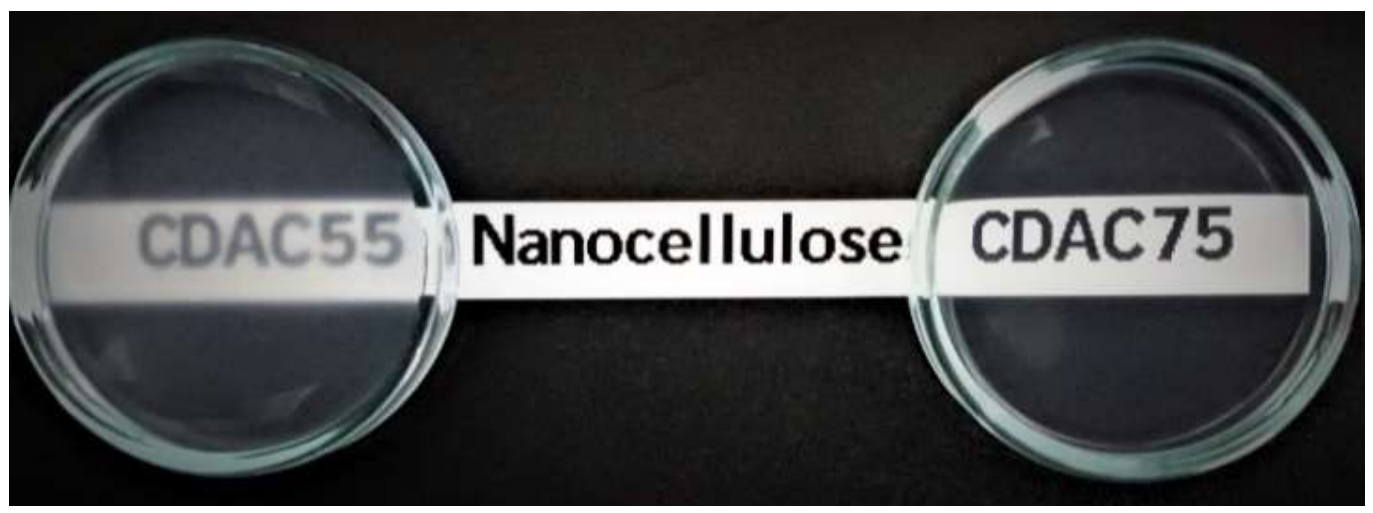

Figure 5. 1\% CDAC55 (left) and CDAC75 (right) nanocellulose suspensions after mechanical disintegration.

313 The TEM images presented in Figure 6 confirm that both CDAC55 and CDAC75 formed nanosized particles after mechanical disintegration; i.e., individual nanofibrils and nanocrystals with an average width of $4.6 \pm 1.1 \mathrm{~nm}$ and $5.7 \pm 1.3 \mathrm{~nm}$ were detected separately. Notably, CDAC75 generally consisted of shorter particles with a more rod-like structure that corresponded to cellulose nanocrystals,(Klemm et al., 2011) while CDAC55 mainly consisted of elongated and flexible nanofibrils. Therefore, the TEM images indicated that the morphology of nanocellulose could be tailored by the reaction conditions of AhG DES treatment, and that the nanofibrillation products of CDAC55 and CDAC75 were mainly CNFs and CNCs, respectively. The CNCs produced from AhG DES had a smaller width than previously reported with acidic DES (9-17 nm)(J. A. Sirviö, Visanko, \& Liimatainen, 2016), while the CNFs had comparable width to those fabricated using DES-mediated succinylation (2-7 nm).(Selkälä et al., 2016) Besides, there were fewer but more dispersed web-like nanofibrous individual CNF or CNC structures observed from AhG DES-cationized nanocelluloses, which is different from the nanocelluloses obtained from urea-based DES pretreatment.(P. Li et al., 2017; J. A. Sirviö, Visanko, et al., 2015; Suopajärvi et al., 2017b) In addition to individual CNFs and CNCs, nanocellulose bundles (e.g., sequential periodate-chlorite oxidized nanofibrils with a width of $25 \pm 6 \mathrm{~nm}(\mathrm{H}$. Liimatainen et al., 2012)) were rarely observed in both AhG DES-cationized nanocellulose samples; this finding is similar to that for nanocelluloses obtained from TEMPO-oxidization.(Habibi, Chanzy, \& Vignon, 2006; 
Saito, Kimura, Nishiyama, \& Isogai, 2007) Overall, the AhG DES-cationized nanocelluloses had very similar behaviors to previously reported phosphonated nanocelluloses.(J. A. Sirviö, Hasa, et al., 2015) These findings indicate that according to the aldehyde content of DAC and charge density of CDAC, AhG DES combined with mechanical nanofibrillation led to the formation of cationic CNFs or CNCs. In the literature, periodate oxidation of cellulose is suggested to take place in clusters: that is, periodate molecules that are being formed preferentially react with the noncrystalline locations of celluloses near the previously oxidized regions.(Kim, Kuga, Wada, Okano, \& Kondo, 2000; J. A. Sirviö, Hasa, et al., 2015) Therefore, the high degree of oxidation (DAC75) results in partial dissolution of the cellulose and breaking up of the fibers into short nanocrystals.

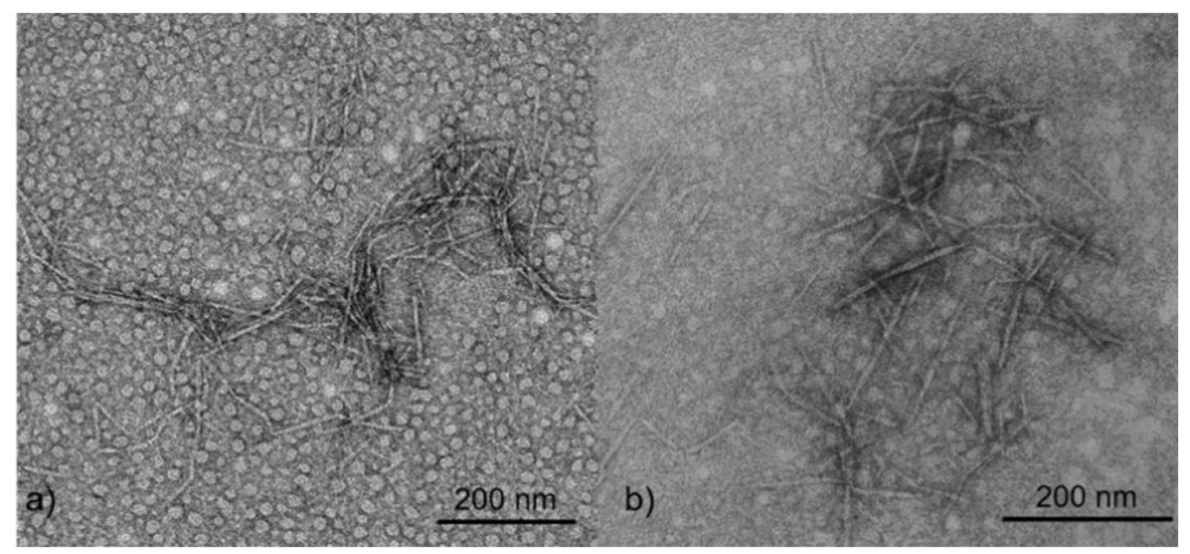

Figure 6. TEM images of nanofibrillated (a) CDAC55 and (b) CDAC75.

\subsection{Recycling of AhG DES}

Aminoguanidine hydrochloride started to precipitate in the original AhG DES at room temperature (Figure 7a). However, even after the reaction and recycling, the AhG DES formed a clear eutectic liquid at room temperature without any visible precipitation. This may be explained by the introduction of impurities, such as ethanol and water, which may promote the dissolution of aminoguanidine hydrochloride. The AhG DES maintained a clear liquid appearance after five 


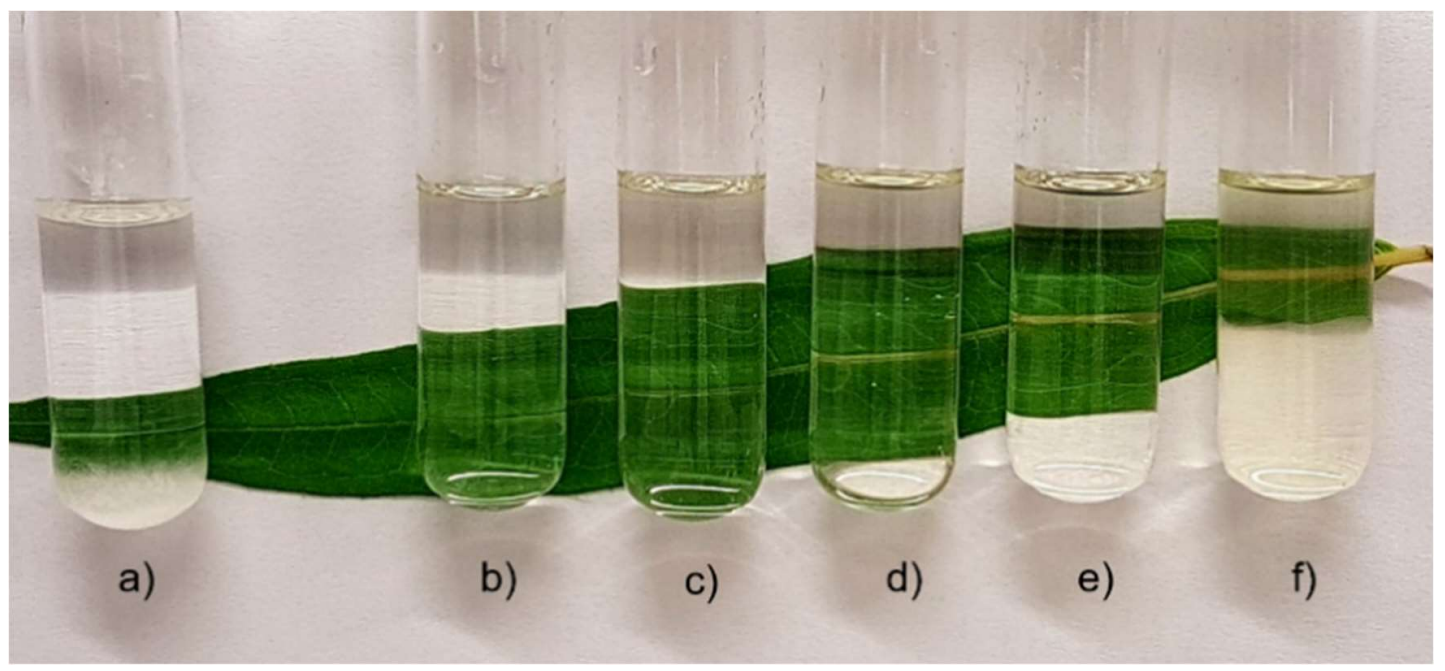

Figure 7. The original AhG DES (a), and recycled AhG DES (b-f) after one to five times of reuse at room temperature.

355 During the recycling of the AhG DES, the yield of DES was slightly reduced after prolonged recycling. The decrease in the yield may be a result of the consumption of aminoguanidine hydrochloride as a result of reaction with the aldehyde groups of DAC. Theoretically, $1.81 \%$ of aminoguanidine hydrochloride was consumed in a single reaction cycle. Therefore, there was clear decreased mass of DES can be seen after first cycle. However, in some cases, the chemical mass of recycled AhG DES was over 100\%, which most likely was a result of the impurities (e.g., water and ethanol) that were tightly bonded and could not be fully removed by evaporation.(van Osch,

362 Zubeir, van den Bruinhorst, Rocha, \& Kroon, 2015) Although the introduction of water often affects the properties of DES (Du, Zhao, Chen, Birbilis, \& Yang, 2016), the cationization reaction efficiency of AhG DES was not affected by impurities from the recycling procedure. As the polyelectrolyte titration results showed, both the original AhG DES and the recycled AhG DES were able to deliver DACs with the same level of cationic charge density after a 10-min reaction 
at $70^{\circ} \mathrm{C}$ (Table 1), the charge densities of CDAC55 and CDAC75 being around 1 and $1.2 \mathrm{mmol} \mathrm{g}^{-}$

$368{ }^{1}$, respectively. It was also noted that the charge density value increased after mechanical

369 disintegration; that is, compared to their precursors, the charge density of nanocelluloses from

370 CDAC55 and CDAC75 was $39 \%$ and $42 \%$ higher, respectively. It seems that some of the cationic

371 groups inside the CDAC fibers became accessible to the large polymer PES-Na, which was used

372 for polyelectrolyte titration after mechanical nanofibrillation (Table 1).

373 Table 1. Summary of the yield of recycled AhG DES and the yield and charge density of CDACs

\begin{tabular}{c|ccc|ccc}
\hline \multicolumn{2}{c}{ Product } & \multicolumn{3}{c}{ CDAC55 } & \multicolumn{3}{c}{ CDAC75 } \\
\hline \multirow{2}{*}{ Cycle } & $\begin{array}{c}\text { Yield of } \\
\text { AhG DES }\end{array}$ & $\begin{array}{c}\text { Yield of } \\
\text { CDAC55 }\end{array}$ & $\begin{array}{c}\text { Charge } \\
\text { density }\end{array}$ & $\begin{array}{c}\text { Yield of } \\
\text { AhG DES }\end{array}$ & $\begin{array}{c}\text { Yield of } \\
\text { CDAC75 }\end{array}$ & $\begin{array}{c}\text { Charge } \\
\text { density }\end{array}$ \\
I & $(\%)$ & $(\%)$ & $\left(\mathrm{mmol} \mathrm{g}^{-1}\right)$ & $(\%)$ & $(\%)$ & 1.206 \\
II & $100 \pm 3.5$ & $107 \pm 2.5$ & 0.918 & $100 \pm 2.5$ & $116 \pm 1.5$ & 1.132 \\
III & $107 \pm 2.0$ & $98 \pm 1.0$ & 1.049 & $106 \pm 1.5$ & $110 \pm 1.0$ & 1.160 \\
IV & $103 \pm 0.5$ & $99 \pm 0.5$ & 0.942 & $102 \pm 2.0$ & $110 \pm 0.5$ & 1.180 \\
V & $100 \pm 1.5$ & $98 \pm 0.5$ & 1.026 & $96 \pm 2.5$ & $108 \pm 1.5$ & 1.221
\end{tabular}

376 Compared with previously reported glycerol-choline chloride DES (Delgado-Mellado et al., 377 2018), the original AhG DES showed similar results from thermogravimetric analysis (Figure 8).

378 I.e., AhG DES had only one-step mass loss caused by the evaporation of glycerol and 379 simultaneously thermal decomposition of aminoguanidine hydrochloride. It was also notable that 

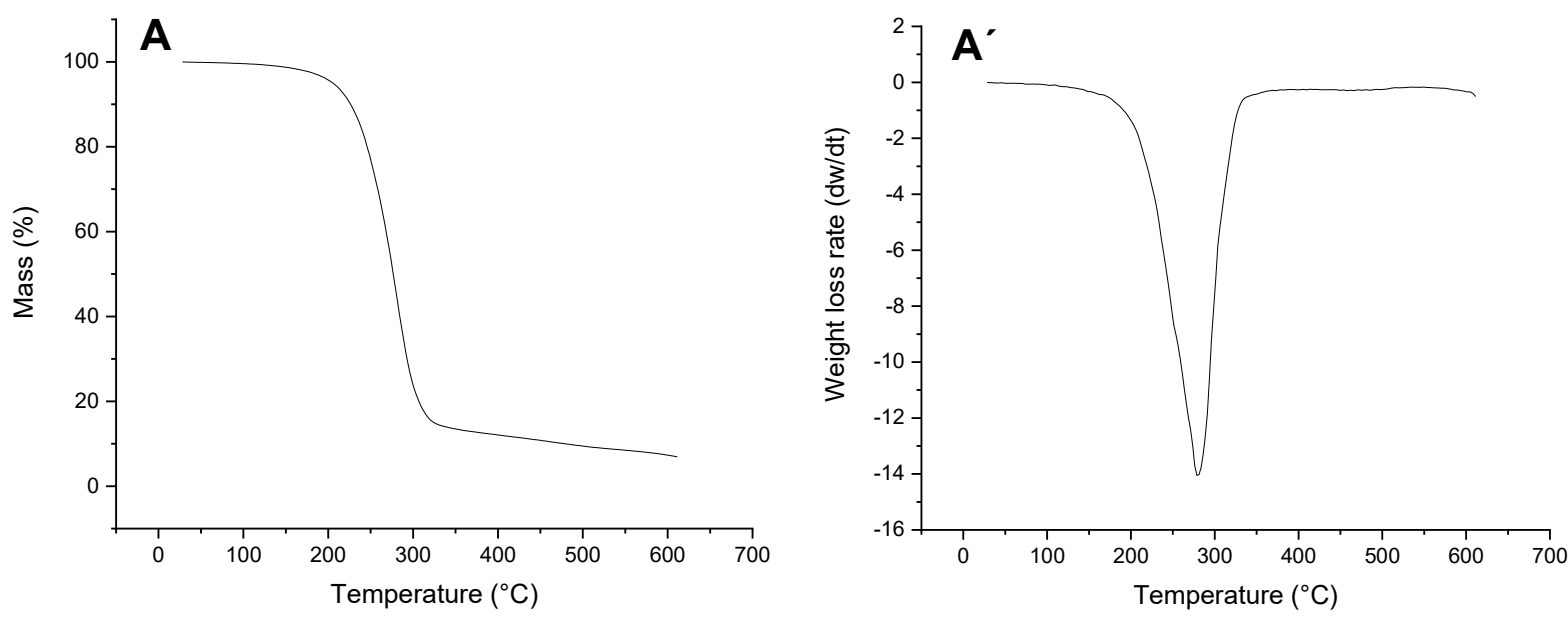

Figure 8. TGA and the first derivate of TGA of the original AhG DES at air condition.

\section{Conclusion}

The AhG DES formed by aminoguanidine hydrochloride and glycerol was found to be an effective and recyclable medium and reagent for the production of cationic celluloses from DAC under mild conditions $\left(70^{\circ} \mathrm{C}\right.$ for $\left.10 \mathrm{~min}\right)$. The DES was reused five times by a simple distillation procedure, and the recycled DES exhibited similar reaction efficiency to the original DES. In addition, no additional chemicals were used during the recycling, which further improved the

391 feasibility of using the AhG DES as a cationization medium. According to the initial aldehyde content of DACs, the cationized cellulose could be disintegrated to highly cationic CNFs or CNCs. Individual CNFs and CNCs had a width of around $5 \mathrm{~nm}$, which indicates that this recyclable AhG DES presents an efficient and green option for functionalized nanocellulose production. 
The study was supported by Safewood (Tekes and European Regional Development Fund: 3368/31/2015) and Bionanochemicals (Academy of Finland Grant: 298295) Projects.

398

399

400

401

402

403

404

405

406

407

408

409

410

411

412

413

414

415

416

\section{REFERENCES}

Abbott, A. P., Cullis, P. M., Gibson, M. J., Harris, R. C., \& Raven, E. (2007). Extraction of glycerol from biodiesel into a eutectic based ionic liquid. Green Chemistry, 9(8), 868. https://doi.org/10.1039/b702833d

Abbott, A. P., Harris, R. C., Ryder, K. S., D’Agostino, C., Gladden, L. F., \& Mantle, M. D. (2011). Glycerol eutectics as sustainable solvent systems. Green Chem., 13(1), 82-90. https://doi.org/10.1039/C0GC00395F

Alonso, D. A., Baeza, A., Chinchilla, R., Guillena, G., Pastor, I. M., \& Ramón, D. J. (2016). Deep Eutectic Solvents: The Organic Reaction Medium of the Century. European Journal of Organic Chemistry, 2016(4), 612-632. https://doi.org/10.1002/ejoc.201501197

Araki, J., Wada, M., Kuga, S., \& Okano, T. (1998). Flow properties of microcrystalline cellulose suspension prepared by acid treatment of native cellulose. Colloids and Surfaces A: Physicochemical and Engineering Aspects, 142(1), 75-82. Retrieved from http://www.sciencedirect.com/science/article/pii/S092777579800404X

Baati, R., Magnin, A., \& Boufi, S. (2017). High Solid Content Production of Nanofibrillar Cellulose via Continuous Extrusion. ACS Sustainable Chemistry \& Engineering, 5(3), 2350-2359. https://doi.org/10.1021/acssuschemeng.6b02673 
Bondeson, D., Mathew, A., \& Oksman, K. (2006). Optimization of the isolation of nanocrystals from microcrystalline cellulose by acid hydrolysis. Cellulose, 13(2), 171-180. https://doi.org/10.1007/s10570-006-9061-4

Camarero Espinosa, S., Kuhnt, T., Foster, E. J., \& Weder, C. (2013). Isolation of Thermally Stable Cellulose Nanocrystals by Phosphoric Acid Hydrolysis. Biomacromolecules, 14(4), 1223 1230. https://doi.org/10.1021/bm400219u

Carrillo, C. A., Laine, J., \& Rojas, O. J. (2014). Microemulsion Systems for Fiber Deconstruction into Cellulose Nanofibrils. ACS Applied Materials \& Interfaces, 6(24), 22622-22627. https://doi.org/10.1021/am5067332

Clayden, J., Greeves, N., \& Warren, S. (2012). Organic Chemistry. OUP Oxford.

Corrêa, A. C., de Morais Teixeira, E., Pessan, L. A., \& Mattoso, L. H. C. (2010). Cellulose nanofibers from curaua fibers. Cellulose, 17(6), 1183-1192. https://doi.org/10.1007/s10570-010-9453-3

Cravotto, G., Orio, L., Gaudino, E. C., Martina, K., Tavor, D., \& Wolfson, A. (2011). Efficient Synthetic Protocols in Glycerol under Heterogeneous Catalysis. ChemSusChem, 4(8), 1130-1134. https://doi.org/10.1002/cssc.201100106

Credou, J., \& Berthelot, T. (2014). Cellulose: from biocompatible to bioactive material. J. Mater. Chem. B, 2(30), 4767-4788. https://doi.org/10.1039/C4TB00431K

Cruz, H., Jordão, N., \& Branco, L. C. (2017). Deep eutectic solvents (DESs) as low-cost and green electrolytes for electrochromic devices. Green Chem., 19(7), 1653-1658. https://doi.org/10.1039/C7GC00347A 
Dash, R., Elder, T., \& Ragauskas, A. J. (2012). Grafting of model primary amine compounds to cellulose nanowhiskers through periodate oxidation. Cellulose, 19(6), 2069-2079. https://doi.org/10.1007/s10570-012-9769-2

Delgado-Mellado, N., Larriba, M., Navarro, P., Rigual, V., Ayuso, M., García, J., \& Rodríguez, F. (2018). Thermal stability of choline chloride deep eutectic solvents by TGA/FTIR-ATR analysis. Journal of Molecular Liquids, 260, 37-43. https://doi.org/10.1016/j.molliq.2018.03.076

Díaz-Álvarez, A. E., Crochet, P., \& Cadierno, V. (2011). Ruthenium-catalyzed reduction of allylic alcohols using glycerol as solvent and hydrogen donor. Catalysis Communications, 13(1), 91-96. https://doi.org/10.1016/j.catcom.2011.07.006

Du, C., Zhao, B., Chen, X.-B., Birbilis, N., \& Yang, H. (2016). Effect of water presence on choline chloride-2urea ionic liquid and coating platings from the hydrated ionic liquid. Scientific Reports, 6(1). https://doi.org/10.1038/srep29225

Eyley, S., \& Thielemans, W. (2011). Imidazolium grafted cellulose nanocrystals for ion exchange $\begin{array}{llll}\text { applications. } & \text { Chemical } & \text { Communications, } & 47(14),\end{array}$ https://doi.org/10.1039/c0cc05359g

García, J. I., García-Marín, H., \& Pires, E. (2014). Glycerol based solvents: synthesis, properties and applications. Green Chem., 16(3), 1007-1033. https://doi.org/10.1039/C3GC41857J

Gu, Y., \& Jérôme, F. (2010). Glycerol as a sustainable solvent for green chemistry. Green Chemistry, 12(7), 1127. https://doi.org/10.1039/c001628d

Guigo, N., Mazeau, K., Putaux, J.-L., \& Heux, L. (2014). Surface modification of cellulose microfibrils by periodate oxidation and subsequent reductive amination with benzylamine: 
a topochemical study. Cellulose, 21(6), 4119-4133. https://doi.org/10.1007/s10570-0140459-0

462

463

464

Habibi, Y., Chanzy, H., \& Vignon, M. R. (2006). TEMPO-mediated surface oxidation of cellulose whiskers. Cellulose, 13(6), 679-687. https://doi.org/10.1007/s10570-006-9075-y

Hasani, M., Cranston, E. D., Westman, G., \& Gray, D. G. (2008). Cationic surface functionalization of cellulose nanocrystals. Soft Matter, 4(11), 2238-2244. https://doi.org/10.1039/B806789A

Henriksson, M., Henriksson, G., Berglund, L. A., \& Lindström, T. (2007). An environmentally friendly method for enzyme-assisted preparation of microfibrillated cellulose (MFC) nanofibers. European Polymer Journal, 43(8), 3434-3441. https://doi.org/10.1016/j.eurpolymj.2007.05.038

Hernáiz, M. J., Alcántara, A. R., García, J. I., \& Sinisterra, J. V. (2010). Applied Biotransformations in Green Solvents. Chemistry - A European Journal, 16(31), 94229437. https://doi.org/10.1002/chem.201000798

Hua, K., Carlsson, D. O., Ålander, E., Lindström, T., Strømme, M., Mihranyan, A., \& Ferraz, N. (2014). Translational study between structure and biological response of nanocellulose from wood and green algae. RSC Adv., 4(6), 2892-2903. https://doi.org/10.1039/C3RA45553J

Ilgen, F., Ott, D., Kralisch, D., Reil, C., Palmberger, A., \& König, B. (2009). Conversion of carbohydrates into 5-hydroxymethylfurfural in highly concentrated low melting mixtures. Green Chemistry, 11(12), 1948. https://doi.org/10.1039/b917548m 
Imperato, G., König, B., \& Chiappe, C. (2007). Ionic Green Solvents from Renewable Resources. European Journal of Organic Chemistry, 2007(7), 1049-1058. https://doi.org/10.1002/ejoc.200600435

Jasmani, L., Eyley, S., Wallbridge, R., \& Thielemans, W. (2013). A facile one-pot route to cationic cellulose nanocrystals. Nanoscale, 5(21), 10207. https://doi.org/10.1039/c3nr03456a

Jin, L., Li, W., Xu, Q., \& Sun, Q. (2015). Amino-functionalized nanocrystalline cellulose as an adsorbent for anionic dyes. Cellulose, 22(4), 2443-2456. https://doi.org/10.1007/s10570015-0649-4

Kenawy, I. M., Hafez, M. A. H., Ismail, M. A., \& Hashem, M. A. (2017). Adsorption of Cu(II), $\mathrm{Cd}(\mathrm{II}), \mathrm{Hg}(\mathrm{II}), \mathrm{Pb}(\mathrm{II})$ and $\mathrm{Zn}(\mathrm{II})$ from aqueous single metal solutions by guanyl-modified cellulose. International Journal of Biological Macromolecules. https://doi.org/10.1016/j.ijbiomac.2017.10.017

Khaksar, S. (2015). Fluorinated alcohols: A magic medium for the synthesis of heterocyclic compounds. Journal of Fluorine Chemistry, 172, 51-61. https://doi.org/10.1016/j.jfluchem.2015.01.008

Kim, U.-J., Kuga, S., Wada, M., Okano, T., \& Kondo, T. (2000). Periodate Oxidation of Crystalline Cellulose. Biomacromolecules, $1(3)$ 488-492. https://doi.org/10.1021/bm0000337

Klemm, D., Kramer, F., Moritz, S., Lindström, T., Ankerfors, M., Gray, D., \& Dorris, A. (2011). Nanocelluloses: A New Family of Nature-Based Materials. Angewandte Chemie International Edition, 50(24), 5438-5466. https://doi.org/10.1002/anie.201001273 
Kong, P. S., Aroua, M. K., Daud, W. M. A. W., Lee, H. V., Cognet, P., \& Pérès, Y. (2016). Catalytic role of solid acid catalysts in glycerol acetylation for the production of bioadditives: a review. $R S C A d v$., 6(73), 68885-68905. https://doi.org/10.1039/C6RA10686B

Laitinen, O., Hartmann, R., Sirviö, J. A., Liimatainen, H., Rudolph, M., Ämmälä, A., \& Illikainen, M. (2016). Alkyl aminated nanocelluloses in selective flotation of aluminium oxide and quartz. Chemical Engineering Science, 144, 260-266. https://doi.org/10.1016/j.ces.2016.01.052

Laitinen, Ossi, Kemppainen, K., Ämmälä, A., Sirviö, J. A., Liimatainen, H., \& Niinimäki, J. (2014). Use of Chemically Modified Nanocelluloses in Flotation of Hematite and Quartz. Industrial \& Engineering Chemistry Research, 53(52), 20092-20098. https://doi.org/10.1021/ie503415t

Laitinen, Ossi, Ojala, J., Sirviö, J. A., \& Liimatainen, H. (2017). Sustainable stabilization of oil in water emulsions by cellulose nanocrystals synthesized from deep eutectic solvents. Cellulose, 24(4), 1679-1689. https://doi.org/10.1007/s10570-017-1226-9

Laitinen, Ossi, Suopajärvi, T., Österberg, M., \& Liimatainen, H. (2017). Hydrophobic, Superabsorbing Aerogels from Choline Chloride-Based Deep Eutectic Solvent Pretreated and Silylated Cellulose Nanofibrils for Selective Oil Removal. ACS Applied Materials \& Interfaces, 9(29), 25029-25037. https://doi.org/10.1021/acsami.7b06304

Leung, A. C. W., Hrapovic, S., Lam, E., Liu, Y., Male, K. B., Mahmoud, K. A., \& Luong, J. H. T. (2011). Characteristics and Properties of Carboxylated Cellulose Nanocrystals Prepared from a Novel One-Step Procedure. Small, 7(3), 302-305. https://doi.org/10.1002/smll.201001715 
Li, C.-J., \& Chen, L. (2006). Organic chemistry in water. Chem. Soc. Rev., 35(1), 68-82. https://doi.org/10.1039/B507207G

Li, P., Sirviö, J. A., Haapala, A., \& Liimatainen, H. (2017). Cellulose Nanofibrils from Nonderivatizing Urea-Based Deep Eutectic Solvent Pretreatments. ACS Applied Materials \& Interfaces, 9(3), 2846-2855. https://doi.org/10.1021/acsami.6b13625

Liimatainen, H., Visanko, M., Sirviö, J. A., Hormi, O. E. O., \& Niinimaki, J. (2012). Enhancement of the nanofibrillation of wood cellulose through sequential periodate-chlorite oxidation. Biomacromolecules, 13(5), 1592-1597. https://doi.org/10.1021/bm300319m

Liimatainen, Henrikki, Sirviö, J., Haapala, A., Hormi, O., \& Niinimäki, J. (2011). Characterization of highly accessible cellulose microfibers generated by wet stirred media milling. Carbohydrate Polymers, 83(4), 2005-2010. https://doi.org/10.1016/j.carbpol.2010.11.007

Liimatainen, Henrikki, Sirviö, J., Pajari, H., Hormi, O., \& Niinimäki, J. (2013). Regeneration and Recycling of Aqueous Periodate Solution in Dialdehyde Cellulose Production. Journal of Wood Chemistry and Technology, $33(4)$, $258-266$. https://doi.org/10.1080/02773813.2013.783076

Liimatainen, Henrikki, Suopajärvi, T., Sirviö, J., Hormi, O., \& Niinimäki, J. (2014). Fabrication of cationic cellulosic nanofibrils through aqueous quaternization pretreatment and their use

Lu, Q., Cai, Z., Lin, F., Tang, L., Wang, S., \& Huang, B. (2016). Extraction of Cellulose Nanocrystals with a High Yield of $88 \%$ by Simultaneous Mechanochemical Activation and Phosphotungstic Acid Hydrolysis. ACS Sustainable Chemistry \& Engineering, 4(4), 2165 2172. https://doi.org/10.1021/acssuschemeng.5b01620 
Marsich, L., Bonifacio, A., Mandal, S., Krol, S., Beleites, C., \& Sergo, V. (2012). Poly-1-lysineCoated Silver Nanoparticles as Positively Charged Substrates for Surface-Enhanced Raman Scattering. Langmuir, 28(37), 13166-13171. https://doi.org/10.1021/la302383r

Mohieldin, S. D., Zainudin, E. S., Paridah, M. T., \& Ainun, Z. M. (2011). Nanotechnology in Pulp and Paper Industries: A Review. Key Engineering Materials, 471-472, 251-256. https://doi.org/10.4028/www.scientific.net/KEM.471-472.251

Montanari, S., Roumani, M., Heux, L., \& Vignon, M. R. (2005). Topochemistry of Carboxylated Cellulose Nanocrystals Resulting from TEMPO-Mediated Oxidation. Macromolecules, 38(5), 1665-1671. https://doi.org/10.1021/ma048396c

Moon, R. J., Martini, A., Nairn, J., Simonsen, J., \& Youngblood, J. (2011). Cellulose nanomaterials review: structure, properties and nanocomposites. Chemical Society Reviews, 40(7), 3941. https://doi.org/10.1039/c0cs00108b

Oh, S. Y., Yoo, D. I., Shin, Y., \& Seo, G. (2005). FTIR analysis of cellulose treated with sodium hydroxide and carbon dioxide. Carbohydrate Research, 340(3), 417-428. https://doi.org/10.1016/j.carres.2004.11.027

Ojala, J., Sirviö, J. A., \& Liimatainen, H. (2016). Nanoparticle emulsifiers based on bifunctionalized cellulose nanocrystals as marine diesel oil-water emulsion stabilizers. Chemical Engineering Journal, 288, 312-320. https://doi.org/10.1016/j.cej.2015.10.113

Oksman, K., Mathew, A. P., Bondeson, D., \& Kvien, I. (2006). Manufacturing process of cellulose whiskers/polylactic acid nanocomposites. Composites Science and Technology, 66(15), 2776-2784. https://doi.org/10.1016/j.compscitech.2006.03.002 
Paiva, A., Craveiro, R., Aroso, I., Martins, M., Reis, R. L., \& Duarte, A. R. C. (2014). Natural Deep Eutectic Solvents - Solvents for the 21st Century. ACS Sustainable Chemistry \& Engineering, 2(5), 1063-1071. https://doi.org/10.1021/sc500096j

Qin, Z.-Y., Tong, G., Chin, Y. C. F., \& Zhou, J.-C. (2011). PREPARATION OF ULTRASONICASSISTED HIGH CARBOXYLATE CONTENT CELLULOSE NANOCRYSTALS BY TEMPO OXIDATION.

BioResources, $6(2)$ $1136-1146$. https://doi.org/10.15376/biores.6.2.1136-1146

Saito, T., Kimura, S., Nishiyama, Y., \& Isogai, A. (2007). Cellulose nanofibers prepared by TEMPO-mediated oxidation of native cellulose. Biomacromolecules, 8(8), 2485-2491. https://doi.org/10.1021/bm0703970

Saito, T., Nishiyama, Y., Putaux, J.-L., Vignon, M., \& Isogai, A. (2006). Homogeneous Suspensions of Individualized Microfibrils from TEMPO-Catalyzed Oxidation of Native Cellulose. Biomacromolecules, 7(6), 1687-1691. https://doi.org/10.1021/bm060154s

Schenzel, A., Hufendiek, A., Barner-Kowollik, C., \& Meier, M. A. R. (2014). Catalytic transesterification of cellulose in ionic liquids: sustainable access to cellulose esters. Green Chemistry, 16(6), 3266. https://doi.org/10.1039/c4gc00312h

Segal, L., Creely, J. J., A. E. Martin, J., \& Conrad, C. M. (2016). An Empirical Method for Estimating the Degree of Crystallinity of Native Cellulose Using the X-Ray Diffractometer: Textile Research Journal. https://doi.org/10.1177/004051755902901003

Selkälä, T., Sirviö, J. A., Lorite, G. S., \& Liimatainen, H. (2016). Anionically Stabilized Cellulose Nanofibrils through Succinylation Pretreatment in Urea-Lithium Chloride Deep Eutectic Solvent. ChemSusChem. https://doi.org/10.1002/cssc.201600903 
Shahid, M., Mohammad, F., Chen, G., Tang, R.-C., \& Xing, T. (2016). Enzymatic processing of natural fibres: white biotechnology for sustainable development. Green Chem., 18(8), 2256-2281. https://doi.org/10.1039/C6GC00201C

Singh, B., Lobo, H., \& Shankarling, G. (2011). Selective N-Alkylation of Aromatic Primary Amines Catalyzed by Bio-catalyst or Deep Eutectic Solvent. Catalysis Letters, 141(1), 178-182. https://doi.org/10.1007/s10562-010-0479-9

Siró, I., \& Plackett, D. (2010a). Microfibrillated cellulose and new nanocomposite materials: a review. Cellulose, 17(3), 459-494. https://doi.org/10.1007/s10570-010-9405-y

Siró, I., \& Plackett, D. (2010b). Microfibrillated cellulose and new nanocomposite materials: a review. Cellulose, 17(3), 459-494. https://doi.org/10.1007/s10570-010-9405-y

Sirviö, J. A. (n.d.). Cationization of lignocellulosic fibers with betaine in deep eutectic solvent: facile route to charge stabilized cellulose and wood nanofibers. Carbohydrate Polymers. https://doi.org/10.1016/j.carbpol.2018.06.051

Sirviö, J. A., Anttila, A.-K., Pirttilä, A. M., Liimatainen, H., Kilpeläinen, I., Niinimäki, J., \& Hormi, O. (2014a). Cationic wood cellulose films with high strength and bacterial antiadhesive properties. Cellulose, 21(5), 3573-3583. https://doi.org/10.1007/s10570-014$0351-y$

Sirviö, J. A., Anttila, A.-K., Pirttilä, A. M., Liimatainen, H., Kilpeläinen, I., Niinimäki, J., \& Hormi, O. (2014b). Cationic wood cellulose films with high strength and bacterial antiadhesive properties. Cellulose, 21(5), 3573-3583. https://doi.org/10.1007/s10570-014$0351-y$

Sirviö, J. A., Hasa, T., Ahola, J., Liimatainen, H., Niinimäki, J., \& Hormi, O. (2015). Phosphonated nanocelluloses from sequential oxidative-reductive treatment-Physicochemical 

https://doi.org/10.1016/j.carbpol.2015.06.090

615 Sirviö, J. A., Visanko, M., Heiskanen, J. P., \& Liimatainen, H. (2016). UV-absorbing cellulose

616

617

618

619

620

621

622

623

624

625

626

627

628

629

630

631

632

633

634

635 nanocrystals as functional reinforcing fillers in polymer nanocomposite films. J. Mater. Chem. A, 4(17), 6368-6375. https://doi.org/10.1039/C6TA00900J

Sirviö, J. A., Visanko, M., \& Liimatainen, H. (2015). Deep eutectic solvent system based on choline chloride-urea as a pre-treatment for nanofibrillation of wood cellulose. Green Chemistry, $\quad$ 17(6), 3401-3406. $\quad$ Retrieved from http://pubs.rsc.org/is/content/articlehtml/2015/gc/c5gc00398a

Sirviö, J. A., Visanko, M., \& Liimatainen, H. (2016). Acidic Deep Eutectic Solvents As Hydrolytic Media for Cellulose Nanocrystal Production. Biomacromolecules, 17(9), 3025-3032. https://doi.org/10.1021/acs.biomac.6b00910

Sirviö, J. A., \& Visanko, M. T. (2017). Anionic wood nanofibers produced from unbleached mechanical pulp by highly efficient chemical modification. J. Mater. Chem. A. https://doi.org/10.1039/C7TA05668K

Sirviö, J. A., Visanko, M., Ukkola, J., \& Liimatainen, H. (2018). Effect of plasticizers on the mechanical and thermomechanical properties of cellulose-based biocomposite films. Industrial Crops and Products, 513-521. https://doi.org/10.1016/j.indcrop.2018.06.039

Sirviö, J., Honka, A., Liimatainen, H., Niinimäki, J., \& Hormi, O. (2011). Synthesis of highly cationic water-soluble cellulose derivative and its potential as novel biopolymeric flocculation agent. Carbohydrate Polymers, 86(1), 266-270. https://doi.org/10.1016/j.carbpol.2011.04.046 
Sirvio, J., Hyvakko, U., Liimatainen, H., Niinimaki, J., \& Hormi, O. (2011). Periodate oxidation of cellulose at elevated temperatures using metal salts as cellulose activators. Carbohydrate $\begin{array}{llll}\text { Polymers, } & \text { 83(3), } & \text { 1293-1297. } & \text { Retrieved }\end{array}$ http://www.sciencedirect.com/science/article/pii/S0144861710007691

Smith, E. L., Abbott, A. P., \& Ryder, K. S. (2014). Deep Eutectic Solvents (DESs) and Their Applications. Chemical Reviews, $114(21)$ 11060-11082. https://doi.org/10.1021/cr300162p

Suopajärvi, T., Sirviö, J. A., \& Liimatainen, H. (2017a). Cationic nanocelluloses in dewatering of municipal activated sludge. Journal of Environmental Chemical Engineering, 5(1), 86-92. https://doi.org/10.1016/j.jece.2016.11.021

Suopajärvi, T., Sirviö, J. A., \& Liimatainen, H. (2017b). Nanofibrillation of deep eutectic solventtreated paper and board cellulose pulps. Carbohydrate Polymers, 169, 167-175. https://doi.org/10.1016/j.carbpol.2017.04.009

van Osch, D. J. G. P., Zubeir, L. F., van den Bruinhorst, A., Rocha, M. A. A., \& Kroon, M. C. (2015). Hydrophobic deep eutectic solvents as water-immiscible extractants. Green Chem., 17(9), 4518-4521. https://doi.org/10.1039/C5GC01451D

Visanko, M., Liimatainen, H., Sirviö, J. A., Heiskanen, J. P., Niinimäki, J., \& Hormi, O. (2014). Amphiphilic Cellulose Nanocrystals from Acid-Free Oxidative Treatment: Physicochemical Characteristics and Use as an Oil-Water Stabilizer. Biomacromolecules, 15(7), 2769-2775. https://doi.org/10.1021/bm500628g

Wagle, D. V., Zhao, H., \& Baker, G. A. (2014). Deep Eutectic Solvents: Sustainable Media for Nanoscale and Functional Materials. Accounts of Chemical Research, 47(8), 2299-2308. https://doi.org/10.1021/ar5000488 
Wang, Y., Hou, Y., Wu, W., Liu, D., Ji, Y., \& Ren, S. (2016). Roles of a hydrogen bond donor and a hydrogen bond acceptor in the extraction of toluene from n-heptane using deep eutectic solvents. Green Chem., 18(10), 3089-3097. https://doi.org/10.1039/C5GC02909K

Wolfson, A., Dlugy, C., \& Shotland, Y. (2007). Glycerol as a green solvent for high product yields and selectivities. Environmental Chemistry Letters, 5(2), 67-71. https://doi.org/10.1007/s10311-006-0080-z

Wolfson, A., Dlugy, C., Tavor, D., Blumenfeld, J., \& Shotland, Y. (2006). Baker's yeast catalyzed asymmetric reduction in glycerol. Tetrahedron: Asymmetry, 17(14), 2043-2045. https://doi.org/10.1016/j.tetasy.2006.07.026

Yang, H., \& van de Ven, T. G. M. (2016). Preparation of hairy cationic nanocrystalline cellulose. Cellulose, 23(3), 1791-1801. https://doi.org/10.1007/s10570-016-0902-5

Yu, H., Qin, Z., Liang, B., Liu, N., Zhou, Z., \& Chen, L. (2013). Facile extraction of thermally stable cellulose nanocrystals with a high yield of $93 \%$ through hydrochloric acid hydrolysis under hydrothermal conditions. Journal of Materials Chemistry A, 1(12), 3938. https://doi.org/10.1039/c3ta01150j

Zhang, J., Jiang, N., Dang, Z., Elder, T. J., \& Ragauskas, A. J. (2008). Oxidation and sulfonation of cellulosics. Cellulose, 15(3), 489-496. https://doi.org/10.1007/s10570-007-9193-1

Zhang, K., Sun, P., Liu, H., Shang, S., Song, J., \& Wang, D. (2016). Extraction and comparison of carboxylated cellulose nanocrystals from bleached sugarcane bagasse pulp using two different oxidation methods. Carbohydrate Polymers, 138, 237-243. https://doi.org/10.1016/j.carbpol.2015.11.038 
680

681

682

683

684

685

686

687

688

689

690

691

692

693

694

695

696

Zhang, Q., De Oliveira Vigier, K., Royer, S., \& Jérôme, F. (2012). Deep eutectic solvents: syntheses, properties and applications. Chemical Society Reviews, 41(21), 7108. https://doi.org/10.1039/c2cs35178a

Zhang, W., Barone, J. R., \& Renneckar, S. (2015). Biomass Fractionation after Denaturing Cell Walls by Glycerol Thermal Processing. ACS Sustainable Chemistry \& Engineering, 3(3), 413-420. https://doi.org/10.1021/sc500564g

Zhang, Y., Jiang, J., \& Chen, Y. (1999). Synthesis and antimicrobial activity of polymeric guanidine and biguanidine salts. Polymer, 40(22), 6189-6198. Retrieved from http://www.sciencedirect.com/science/article/pii/S0032386198008283

Zhao, H., \& Baker, G. A. (2013). Ionic liquids and deep eutectic solvents for biodiesel synthesis: a review. Journal of Chemical Technology \& Biotechnology, 88(1), 3-12. https://doi.org/10.1002/jctb.3935

Zhou, Y., Khan, T. M., Liu, J.-C., Fuentes-Hernandez, C., Shim, J. W., Najafabadi, E., ... Kippelen, B. (2014). Efficient recyclable organic solar cells on cellulose nanocrystal substrates with a conducting polymer top electrode deposited by film-transfer lamination. Organic Electronics, 15(3), 661-666. https://doi.org/10.1016/j.orgel.2013.12.018 